Gut and Liver, Vol. 11, No. 1, January 2017, pp. 47-54

\title{
Factors That Affect Stent-Related Complications in Patients with Malignant Obstruction of the Esophagus or Gastric Cardia
}

\author{
Hiroyasu Iwasaki ${ }^{1}$, Takashi Mizushima ${ }^{1}$, Yuta Suzuki ${ }^{1}$, Shigeki Fukusada ${ }^{1}$, Kenta Kachi ${ }^{1}$, Takanori Ozeki ${ }^{1}$, Kaiki Anbe $^{1}$, \\ Hironobu Tsukamoto ${ }^{1}$, Fumihiro Okumura ${ }^{1}$, Takashi Joh ${ }^{2}$, and Hitoshi Sano ${ }^{1}$ \\ ${ }^{1}$ Department of Gastroenterology, Gifu Prefectural Tajimi Hospital, Tajimi, and ${ }^{2}$ Department of Gastroenterology and Metabolism, Nagoya City \\ University Graduate School of Medical Sciences, Nagoya, Japan
}

\section{See editorial on page 1.}

Background/Aims: Self-expandable metallic stent (SEMS) placement is effective for dysphagia that results from malignant obstruction of the esophagus or gastric cardia; however, stent-related complications may be life-threatening. Thus, the goal of this study was to identify risk factors associated with complications following esophageal stenting. Methods: Of the 71 patients who underwent SEMS placement for dysphagia as a result of malignant stricture of the esophagus or gastric cardia, 53 patients with squamous cell carcinoma or adenocarcinoma, without previous SEMS placement, without a fistula, and without recurrent tumor after surgery were retrospectively identified. The occurrence of stent-related complications was used as an endpoint. Results: Stentrelated complications were identified in 26 patients (49.1\%), and major complications occurred in 14 patients (26.4\%). The use of an Ultraflex stent (odds ratio [OR], 6.81; 95\% confidence interval [Cl], 1.54 to 30.00; $p=0.011$ ) and prior chemotherapy (OR, 6.13; 95\% Cl, 1.46 to 25.70; $p=0.013$ ) were significantly associated with stent-related complications. Moreover, the use of an Ultraflex stent (OR, 19.60; 95\% Cl, 2.26 to $170.00 ; p=0.007)$ and prior radiation (OR, 25.70; $95 \% \mathrm{Cl}, 2.37$ to $280.00 ; \mathrm{p}=0.008$ ) significantly increased the risk of major complications. Conclusions: The use of an Ultraflex stent and prior radiation and/or chemotherapy may represent risk factors for complications following esophageal SEMS placement. (Gut Liver 2017;11:47-54)

Key Words: Esophageal stent; Risk factors; Complication; Radiation; Chemotherapy

\section{INTRODUCTION}

Self-expandable metallic stents (SEMS) are effective in the management of dysphagia in patients with malignant stenosis of the esophagus or gastric cardia. ${ }^{1-3}$ However, stentrelated complications, such as bleeding, perforation, esophagobronchial fistula, aspiration pneumonia, persistent pain, and gastroesophageal reflux, can occur and may be life-threatening. Previous studies have reported that the rates of mortality associated with esophageal stent placement are 3.9\% to $27.2 \%$. $^{3-8}$ Therefore, it is important to select the patients with a low risk of stent-related complications.

Previous studies reported that prior radiation and/or chemotherapy increased the risk of life-threatening complications after esophageal SEMS placement, ${ }^{4,89}$ whereas another report suggested that the incidence of severe complications after SEMS placement was not affected by prior radiation and/or chemotherapy. ${ }^{10}$ Therefore, the relationship between prior therapy and complications after SEMS intubation remains controversial, and international consensus guidelines for the management of palliative treatment for esophageal cancer do not certify prior radiation and/or chemotherapy as contraindications for esophageal stent placement. ${ }^{11,12}$

Several reports have been published concerning the palliation of patients with malignant dysphagia via the insertion of different types of metal stents. Siersema et al. ${ }^{13}$ reported that procedure-related complications were more common with the covered Gianturco-Z stent (Cook Medical, Bloomington, IN, USA) than with the covered Flamingo Wallstent or the covered Ultraflex stent (Boston Scientific, Natick, MA, USA), although May et al. ${ }^{14}$ found no differences in the occurrence of complications and recurrence of dysphagia among patients who received

Correspondence to: Hiroyasu Iwasaki

Department of Gastroenterology, Gifu Prefectural Tajimi Hospital, 161-5 Maehata-cho, Tajimi 507-8522, Japan

Tel: +81-572-22-5311, Fax: +81-572-25-1246, E-mail: iwasaki-hiroyasu@tajimi-hospital.jp

Received on March 30, 2016. Revised on May 11, 2016. Accepted on May 18, 2016. Published online October 13,2016

pISSN 1976-2283 eISSN 2005-1212 https://doi.org/10.5009/gnl16172

@ This is an Open Access article distributed under the terms of the Creative Commons Attribution Non-Commercial License (http://creativecommons.org/licenses/by-nc/4.0) which permits unrestricted non-commercial use, distribution, and reproduction in any medium, provided the original work is properly cited. 
an uncovered Ultraflex stent, an uncovered Wallstent, or a covered Gianturco-Z stent. However, the Wallstent, Gianturco$\mathrm{Z}$ stent, and Flamingo Wallstent are not commonly available or utilized in Japan. Although Verschuur et al. ${ }^{15}$ reported that there were no differences in complications among the Ultraflex stent, the Polyflex stent (Boston Scientific), and the Niti-S stent (Taewoong Medical, Gimpo, Korea), it has been suggested that stentrelated complications might differ according to the properties of each stent behavior.

Therefore, the aim of this study was to identify risk factors for complications for patients who undergo esophageal stenting for management of dysphagia due to malignant esophageal or gastric cardia stenosis.

\section{MATERIALS AND METHODS}

\section{Patients}

Data were collected from the medical records of patients who underwent SEMS placement for malignant obstruction of the esophagus or gastric cardia at Gifu Prefectural Tajimi Hospital from January 2006 to May 2015. Exclusion criteria were unidentified tumor histology, previous metal stent placement, a fistula between the esophagus and respiratory tree, and recurrent tumor after esophagectomy or gastrectomy. All data, including age, gender, histology, tumor length, reason for palliative treatment, serum albumin, stent length, expansion rate on stent placement, location of tumor, type of stent, and prior radiation and/or chemotherapy were noted for all patients, and serum albumin at the time of decision to place esophageal
SEMS was used for the analysis conducted in this study.

The patients were graded according to the ability to eat and/ or swallow as follows: $0=$ patients were able to eat normal diet; $1=$ patients were able to eat some solid foods; $2=$ patients were able to eat semi-solid foods; $3=$ patients were able to swallow liquids only; $4=$ patients were unable to swallow anything. ${ }^{16}$

Data were retrospectively analyzed, and informed consent was obtained from all patients. The study protocol conformed to the ethical guidelines of the 1975 Declaration of Helsinki (sixth revision, 2008), and an Institutional Review Board approved the protocol for this research project.

\section{Placement of stents}

During stent insertion, all patients were consciously sedated with midazolam and pentazocine. After endoscope insertion, esophagography was performed to measure tumor length. If it was impossible to pass the tumor with an endoscope, we used the cannulas for endoscopic retrograde cholangiopancreatography for wire passage. If needed, the upper and/or lower tumor margins were marked with short radio-opaque sticks attached to the surface of the patient body. The stent was expanded under fluoroscopic monitoring followed by esophagoscopy for confirmation of stent location and expansion.

Three types of stent were used (Fig. 1):

(1) Partially covered or uncovered Ultraflex stents (Boston Scientific) in lengths of 10 and $15 \mathrm{~cm}$, and diameters of $23 \mathrm{~mm}$ (proximal), $18 \mathrm{~mm}$ (middle), and $23 \mathrm{~mm}$ (distal). The partially covered stent is uncovered at both ends over a distance of 1.5 $\mathrm{cm}$.

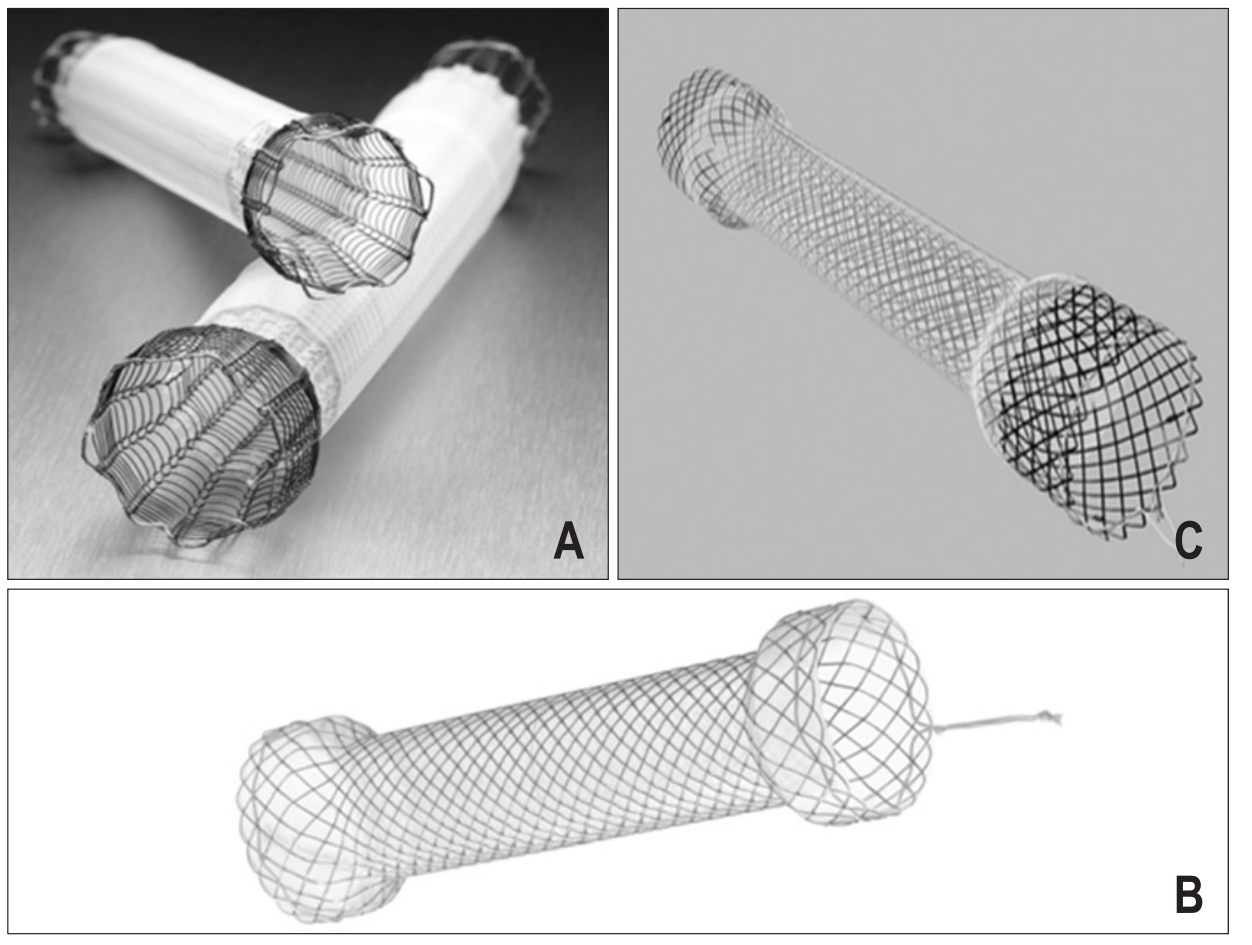

Fig. 1. Three stent types that were used in the present study: (A) Ultraflex stent (Boston Scientific); (B) Niti-S stent (Taewoong Medical); and (C) Evolution stent (Cook Medical). 
(2) Partially covered or uncovered Niti-S stents (Taewoong Medical) in lengths of 8, 10, 12, and $15 \mathrm{~cm}$, and diameters of 26 $\mathrm{mm}$ (proximal), $18 \mathrm{~mm}$ (middle), and $26 \mathrm{~mm}$ (distal). The partially covered stent is uncovered at both ends over a distance of $1.2 \mathrm{~cm}$.

(3) Partially covered Evolution stents (Cook Medical) in lengths of $8,10,12.5$, and $15 \mathrm{~cm}$, and diameters of $25 \mathrm{~mm}$ (proximal), $20 \mathrm{~mm}$ (middle), and $25 \mathrm{~mm}$ (distal). The stent is uncovered at both ends over a distance of $1.5 \mathrm{~cm}$.

\section{Definitions}

Clinical success was defined as success in reduction of more than 1 in the dysphagia score after stent placement. Expansion rate was defined as the rate of the width of the point where the stent was the narrowest to regulation diameter when the stent was deployed. Hemorrhage, perforation, fistula, aspiration pneumonia, and fever were defined as major complications, while pain and gastroesophageal reflux were defined as minor complications. Hemorrhage was defined as hematemesis and/or melena after stent placement which were considered as stent-related complications. We defined a fever over 38 degrees within 7 days after stent insertion, which might reflect micro perforation or an aspiration, as a complication. Pain (as a stentrelated complication) was defined as pain that required an analgesic drug to relieve. Heartburn and/or regurgitation after stent intubation were regarded as gastroesophageal reflux. Recurrent dysphagia (including stent migration) was evaluated separately from complications in this study to focus attention on physical suffering. Patients were categorized into two groups for analysis: (1) those with some stent-related complications (complication [+]); and (2) those without any complications (complication [-]). To reveal factors affecting major complications, patients were also classified into two other groups: (1) those with some major complications (major complication [+]); and (2) those who had no major complications (major complication [-]). In univariate and multivariate analysis, patients with prior concurrent chemoradiotherapy were included as in the "prior radiation group".

\section{Statistical analysis}

All data were analyzed with the Mann-Whitney U test or chisquare test, as appropriate. The survival period was evaluated using the log-rank test (Kaplan-Meier methods). Multivariate analysis was performed with a multiple logistic regression model using a stepwise selection method according to the likelihood ratio. Moreover, logistic regression was used to estimate the odds ratio (OR) and the 95\% confidence interval (CI) of various possible risk factors. The $\mathrm{p}$-values of $<0.05$ were considered to indicate statistical significance.

\section{RESULTS}

\section{Patients}

Among 71 patients who underwent esophageal stent placement, four patients without a tissue diagnosis, two patients with previous SEMS placement, four patients with a fistula between the esophagus and respiratory tree, and eight patients with recurrent tumor after esophagectomy or gastrectomy were excluded. Thus, 53 patients were included in the final analysis (Fig. 2).

Patient characteristics are shown in Table 1. The number of patients given chemotherapy, radiation and concurrent chemoradiotherapy before stent placement was 24 , three, and six, respectively. The median total radiation dose was 60 Gy (range, 10 to 66 Gy). The median time between the completion of radiation and the stent placement was 4.4 months. The median number of cycles of chemotherapy was 3.5 (range, 1 to 31). The number of patients who were treated with first-line chemotherapy, second-

71 Patients who underwent esophageal stent placement for inoperable malignant obstruction of the esophagus or gastric cardia

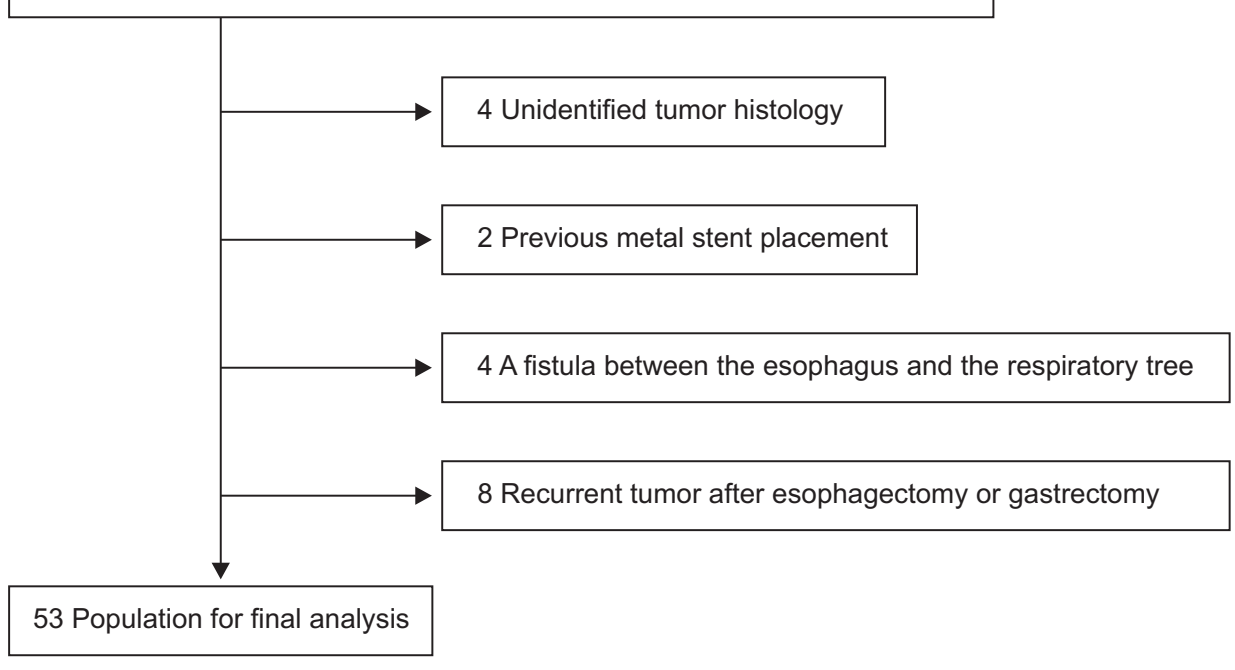

Fig. 2. Patient selection procedure. Of the 71 patients who underwent esophageal stent placement, four patients without a tissue diagnosis, two patients with previous metal stent placement, four patients with a fistula between the esophagus and respiratory tree, and eight patients with a recurrent tumor following esophagectomy or gastrectomy were excluded. Thus, 53 patients were included in the final analysis. 
Table 1. Characteristics of Patients Who Underwent Placement of an Esophageal Stent $(n=53)$

\begin{tabular}{|c|c|}
\hline Characteristic & Value \\
\hline \multicolumn{2}{|l|}{ Sex } \\
\hline Male & $47(88.7)$ \\
\hline Female & $6(11.3)$ \\
\hline Age, yr & $74(51-94)$ \\
\hline Dysphagia score before treatment (median, IQR) & $3(2)$ \\
\hline \multicolumn{2}{|l|}{ Tumor histology } \\
\hline Squamous cell carcinoma & $42(79.2)$ \\
\hline Adenocarcinoma & $11(20.8)$ \\
\hline \multicolumn{2}{|l|}{ Reason for palliative treatment } \\
\hline Advanced age & $9(17.0)$ \\
\hline Metastasis & 21 (39.6) \\
\hline Extensive disease & $10(18.9)$ \\
\hline Poor general condition & $13(24.5)$ \\
\hline Tumor length, $\mathrm{cm}$ & $5.5 \pm 2.2$ \\
\hline \multicolumn{2}{|l|}{ Stent length, $\mathrm{cm}$} \\
\hline Total & $10.7 \pm 2.1$ \\
\hline Covered part only & $8.4 \pm 2.2$ \\
\hline Expansion rate, \% & $56.4 \pm 18.9$ \\
\hline \multicolumn{2}{|l|}{ Location of tumor } \\
\hline Ut & $5(9.4)$ \\
\hline Mt & $25(47.2)$ \\
\hline Lt & $11(20.8)$ \\
\hline Ae+cardia & $12(22.6)$ \\
\hline \multicolumn{2}{|l|}{ Type of stent } \\
\hline Ultraflex stent (partially covered) & $14(26.4)$ \\
\hline Ultraflex stent (uncovered) & $9(17.0)$ \\
\hline Niti-S stent (partially covered) & $28(52.8)$ \\
\hline Niti-S stent (uncovered) & $1(1.9)$ \\
\hline Evolution stent (partially covered) & $1(1.9)$ \\
\hline \multicolumn{2}{|l|}{ Prior radiation and/or chemotherapy } \\
\hline Radiation & $3(5.7)$ \\
\hline Concurrent chemoradiotherapy & $6(11.3)$ \\
\hline Chemotherapy & $24(45.3)$ \\
\hline
\end{tabular}

Data are presented as number (\%), median (range), or mean \pm SD. $\mathrm{IQR}$, interquartile range; Ut, upper thoracic esophagus; Mt, middle thoracic esophagus; Lt, lower thoracic esophagus; Ae, Abdominal esophagus.

line chemotherapy, and third-line or later chemotherapy was 11, eight, and five, respectively. The median time between the end of the chemotherapy and the stent insertion was 1.9 months.

\section{Outcome}

The dysphagia score improved from a median 3 to 1 in most patients at 2 weeks after treatment $(\mathrm{p}<0.001)$ (Table 2). Stentrelated complications were observed in 26 patients (49.1\%), and
Table 2. Outcome Following Insertion of Esophageal or Cardiac Stent $(\mathrm{n}=53)$

\begin{tabular}{lc}
\hline \multicolumn{1}{c}{ Characteristic } & Value \\
\hline Technical success & $51(96.2)$ \\
Clinical success & $42(79.2)$ \\
Dysphagia score 2 wk after treatment (median, IQR) & $1(1)$ \\
30-Day mortality & $7(13.2)$ \\
Median survival in days & 121 \\
Cause of death & \\
Stent-related & $4(7.5)$ \\
Tumor progression & $24(45.3)$ \\
Not related to tumor & $1(1.9)$ \\
Total complications & $26(49.1)$ \\
Hemorrhage* & $3(5.7)$ \\
Perforation* & $4(7.5)$ \\
Fistula* & $1(1.9)$ \\
Fever* & $6(11.3)$ \\
Aspiration pneumonia* & $3(5.7)$ \\
Pain* & $13(24.5)$ \\
Gastroesophageal reflux* & $3(5.7)$ \\
Major complications & $14(26.4)$ \\
Recurrent dysphagia & $12(22.6)$ \\
Tumor overgrowth & $7(13.2)$ \\
Tumor ingrowth & $1(1.9)$ \\
Stent migration & $1(1.9)$ \\
Food bolus impaction & $3(5.7)$ \\
\hline
\end{tabular}

Data are presented as number (\%).

$\mathrm{IQR}$, interquartile range.

*Numbers include patients with one or more complications.

major complications occurred in 14 (26.4\%), including three (5.7\%) with hemorrhage, four (7.5\%) with perforation, one (1.9\%) with fistula, six (11.3\%) with fever, and three (5.7\%) with aspiration pneumonia. Of three patients with hemorrhage, one died from active bleeding, and two required blood transfusion. In four patients with perforation, three died from mediastinitis or empyema caused by perforation, and one patient was successfully treated with another stent insertion to close the rupture. An esophago-respiratory fistula developed in one patient (1.8\%), which was managed with a second stent. Regarding stent-related complications, there were no significant differences between the number of patients with prior chemotherapy or radiation alone and patients with prior concurrent chemoradiotherapy $(\mathrm{n}=18 / 2 / 5, \mathrm{p}=0.848)$. The mean total radiation dose of patients with major complications was not significantly higher than that for patients without major complications (48.3 Gy vs 48.0 Gy, $\mathrm{p}=0.892$ ).

Recurrent dysphagia occurred in 12 patients (22.6\%). Tumor overgrowth was observed at the proximal end of the stent in four patients (7.5\%), at the distal end in one patient (1.9\%), and 
at both ends of the stent in two patients (3.8\%). In one patient (1.9\%) with obstruction of the lower thoracic esophagus, stent migration to the distal portion was found at the time of the endoscopy, and another stent was placed for proximal stenosis.

\section{Clinical risk factors}

Univariate and multivariate analyses for each risk factor when comparing the "complication (+)" group and the "complication (-)" group are shown in Table 3. Age, serum albumin, tumor length, and expansion rate were calculated as sequential values, and squamous cell carcinoma, location of tumor, use of an Ultraflex stent, prior radiation, and prior chemotherapy were used as discriminant values.

In the univariate analysis, age, use of an Ultraflex stent, and prior chemotherapy were significant predictors of complications (age, $\mathrm{p}=0.010$; use of an Ultraflex stent, $\mathrm{p}=0.019$; prior chemotherapy, $p=0.002$ ). In the multivariate analysis for these nine variables using a stepwise selection method by likelihood

Table 3. Univariate and Multivariate Analyses of Patients with Any Complication

\begin{tabular}{|c|c|c|c|c|c|}
\hline \multirow{2}{*}{ Variable } & \multirow{2}{*}{$\begin{array}{l}\text { Complication }(+) \\
\qquad(\mathrm{n}=26)\end{array}$} & \multirow{2}{*}{$\begin{array}{l}\text { Complication }(-) \\
\qquad(\mathrm{n}=27)\end{array}$} & \multirow{2}{*}{$\begin{array}{c}\text { Univariate analysis } \\
\text { p-value }\end{array}$} & \multicolumn{2}{|c|}{ Multivariate analysis } \\
\hline & & & & p-value & OR (95\% CI) \\
\hline Age, yr & 70 (51-87) & 76 (54-94) & 0.010 & 0.106 & $0.94(0.87-1.01)$ \\
\hline Serum albumin, g/dL & $3.0 \pm 0.5$ & $2.9 \pm 0.5$ & 0.539 & - & - \\
\hline Squamous cell carcinoma & $21(80.8)$ & $21(77.8)$ & 0.788 & - & - \\
\hline Tumor length, cm & $5.1 \pm 2.0$ & $5.9 \pm 2.3$ & 0.270 & - & - \\
\hline Expansion rate, \% & $52.6 \pm 19.6$ & $60.0 \pm 17.8$ & 0.135 & - & - \\
\hline \multicolumn{6}{|l|}{ Location of tumor } \\
\hline $\mathrm{Ut}$ & $2(7.7)$ & $3(11.1)$ & 0.964 & - & - \\
\hline Mt & $13(50.0)$ & $12(44.4)$ & 0.897 & - & - \\
\hline Lt & $6(23.1)$ & $5(18.5)$ & 0.944 & - & - \\
\hline Ae+cardia & $5(19.2)$ & 7 (25.9) & 0.800 & - & - \\
\hline Use of Ultraflex stent & $16(61.5)$ & 7 (25.9) & 0.019 & 0.011 & $6.81(1.54-30.00)$ \\
\hline Prior radiation & 7 (26.9) & $2(7.4)$ & 0.127 & - & - \\
\hline Prior chemotherapy & $18(69.2)$ & $6(22.2)$ & 0.002 & 0.013 & $6.13(1.46-25.70)$ \\
\hline
\end{tabular}

Data are presented as median (range), mean $\pm \mathrm{SD}$, or number (\%).

OR, odds ratio; CI, confidence interval; Ut, upper thoracic esophagus; Mt, middle thoracic esophagus; Lt, lower thoracic esophagus; Ae, abdominal esophagus.

Table 4. Univariate and Multivariate Analyses of Patients with Major Complications

\begin{tabular}{|c|c|c|c|c|c|}
\hline \multirow{2}{*}{ Variable } & \multirow{2}{*}{$\begin{array}{l}\text { Major complication }(+) \\
\qquad(\mathrm{n}=14)\end{array}$} & \multirow{2}{*}{$\begin{array}{l}\text { Major complication (-) } \\
\qquad(\mathrm{n}=39)\end{array}$} & \multirow{2}{*}{$\begin{array}{c}\text { Univariate analysis } \\
\text { p-value }\end{array}$} & \multicolumn{2}{|c|}{ Multivariate analysis } \\
\hline & & & & p-value & OR $(95 \% \mathrm{CI})$ \\
\hline Age, yr & $71(51-81)$ & 75 (54-94) & 0.183 & - & - \\
\hline Serum albumin, g/dL & $3.0 \pm 0.6$ & $2.9 \pm 0.5$ & 0.709 & - & - \\
\hline Squamous cell carcinoma & $12(85.7)$ & $30(76.9)$ & 0.755 & - & - \\
\hline Tumor length, $\mathrm{cm}$ & $5.5 \pm 2.0$ & $5.5 \pm 2.3$ & 0.840 & - & - \\
\hline Expansion rate, \% & $51.7 \pm 21.6$ & $58.1 \pm 17.8$ & 0.234 & - & - \\
\hline \multicolumn{6}{|l|}{ Location of tumor } \\
\hline Ut & $2(14.3)$ & $3(7.7)$ & 0.848 & - & - \\
\hline Mt & $7(50.0)$ & $18(46.2)$ & 0.948 & - & - \\
\hline Lt & $4(28.6)$ & $7(17.9)$ & 0.648 & - & - \\
\hline Ae+Cardia & $1(7.1)$ & $11(28.2)$ & 0.214 & - & - \\
\hline Use of Ultraflex stent & 11 (78.6) & $12(30.8)$ & 0.005 & 0.007 & $19.60(2.26-170.00)$ \\
\hline Prior radiation & $6(42.9)$ & $3(7.7)$ & 0.010 & 0.008 & $25.70(2.37-280.00)$ \\
\hline Prior chemotherapy & $10(71.4)$ & $14(35.9)$ & 0.048 & - & - \\
\hline
\end{tabular}

Data are presented as median (range), mean \pm SD, or number (\%).

OR, odds ratio; CI, confidence interval; Ut, upper thoracic esophagus; Mt, middle thoracic esophagus; Lt, lower thoracic esophagus; Ae, abdominal esophagus. 
ratio, use of an Ultraflex stent (OR, 6.81; 95\% CI, 1.54 to 30.00; $\mathrm{p}=0.011)$ and prior chemotherapy (OR, 6.13; 95\% CI, 1.46 to 25.70; $p=0.013$ ) were significantly associated with stent-related complications.

Univariate and multivariate analyses to compare the "major complication (+)" group and "major complication (-)" group are shown in Table 4. Use of an Ultraflex stent, prior radiation, and prior chemotherapy significantly increased the risk of major complications in the univariate analysis (use of an Ultraflex stent, $\mathrm{p}=0.005$; prior radiation, $\mathrm{p}=0.010$; prior chemotherapy, $\mathrm{p}=0.048$ ). The multivariate analysis showed that factors increasing the risk of major complications were the use of an Ultraflex stent (OR, 19.60; 95\% CI, 2.26 to $170.00 ; \mathrm{p}=0.007$ ) and prior radiation (OR, 25.70; 95\% CI, 2.37 to $280.00 ; p=0.008$ ).

\section{DISCUSSION}

The use of SEMS in the management of inoperable malignant stricture of the esophagus and gastric cardia is well established, and endoscopic placement of SEMS has become the first-line palliative option for dysphagia. ${ }^{17}$ For this purpose, we expected that the esophageal SEMS would relieve dysphagia, prevent recurrent dysphagia, and have few complications.

In our study, approximately 50\% of patients who underwent esophageal stent placement suffered complications. Fourteen patients (26.4\%) had major complications, and four patients (7.5\%) died due to severe complications (i.e., hemorrhage and perforation) (Table 2). This study demonstrated that the use of an Ultraflex stent and prior chemotherapy were independent predictors of complications after esophageal SEMS insertion and that major complications after SEMS placement were significantly associated with the use of an Ultraflex stent and prior radiation.

Although some previous studies have reported that anticancer drug-eluting stents and stents loaded with radioactive material are more effective for patients with unresectable esophageal cancer when compared with conventional stents, ${ }^{18,19}$ there were no differences in the efficacy of SEMS to relieve dysphagia between the types of the conventional stent..$^{13,15,20-24}$ Therefore, the difference on efficacy has little impact on the clinicians' selection of the specific type of SEMS. Recurrent dysphagia due to tumor overgrowth or ingrowth, food bolus impaction, and stent migration occurs in about $20 \%$ to $40 \%$ of patients after SEMS placement, ${ }^{3,825}$ and these complications require reintervention. Previous studies reported that recurrent dysphagia occurred more frequently with Ultraflex stents than with Polyflex stents or Niti-S stents, ${ }^{15}$ although Polyflex stents were associated with a high rate of stent migration. ${ }^{15,21}$ Therefore, placement of plastic stents (i.e., Polyflex stents) is not recommended because of the high rates of complications. ${ }^{12,17}$ Thus, we consider it important to choose a stent with a lower risk of restenosis and fewer stentrelated complications. The finding from the present study that the use of an Ultraflex stent is a predictor of stent-related complications might influence clinicians to select alternate stents.

In our study, hemorrhage and perforation were the two critical complications. There are several possible reasons for hemorrhage. First, esophageal SEMS contact and damage the mucosa and the tumor. Second, if the tumor has infiltrated a large artery, such as the aorta, pressure from SEMS on the esophageal wall can lead to arterial rupture and massive and lethal bleeding. Metallic stent placement exerts constant pressure on the esophageal wall and the tumor, which can increase the risk of local necrosis, an inflammatory reaction with increased fibrotic activity and degeneration of the muscular layers. ${ }^{26}$ Such changes in the esophageal wall and the tumor, which may cause bleeding and perforation, are related to the properties of stents. In coronary artery stenting, the axial force, in other words, the force required to keep the stent straight after bending is the main predictor of severe adverse cardiac events and restenosis. ${ }^{27}$ The Ultraflex stent has a higher radial force and a lower axial force than the Niti-S stent or Evolution stent. ${ }^{28}$ In our study, patients treated with Ultraflex stents were at higher risk of stentrelated complications than those treated with other stents (i.e., Niti-S stent or Evolution stent). This result might be because of the radial force resulting from stent expansion is associated with tissue damage caused by embedding of the stent in the esophageal wall. In addition, in contrast to the coronary artery, the esophagus is very straight, and the axial force, which might produce injury to the esophageal wall due to poor fit within the lumen, has a lower impact on damage to the esophageal wall than does the radial force.

Moreover, prior radiation therapy was also found to be a significant predictor of major complications in both the univariate and multivariate analyses (Table 4). Although radiation therapy to the esophagus has acute and late toxicity, the late effects of radiation are believed to be due to inflammation and scar formation within the esophageal musculature. ${ }^{29}$ Histologic study has shown epithelial thickening, chronic inflammation, submucosal or muscularis fibrosis, and vasculitis, which may lead to local hypoxemia. ${ }^{30}$ The late effects of radiation therapy are seen 3 or more months after completion of radiation therapy, with a median time to onset of 6 months. ${ }^{31,32}$ In our study, the median time from prior radiation to the esophageal SEMS insertion was approximately 4 months, and two-thirds of patients with prior radiation suffered major complications. This finding supports the idea that the late effects of esophageal radiation therapy have an important role in the occurrence of severe stent-related complications. The esophageal toxicity of radiation therapy is recognized as dose-dependent. Therefore, it is possible that the relationship between prior radiation and stent-related complications is also dose-dependent. Our series cannot confirm this hypothesis, as there was no significant difference in the dose of radiation between patients with prior radiation who developed major complications after stent insertion and patients who did 
not develop major complications. One reason for this result may be that patients with unresectable esophageal cancer are often treated with standard-dose radiation in Japan, so it is difficult to compare them with patients who receive radiation therapy using different doses of radiation therapy. It has been also reported that severe esophageal toxicity is significantly increased when chemotherapy is given concurrently with radiation when compared with sequential chemoradiation or radiation alone. ${ }^{33}$ Chemotherapy is delivered to shrink the tumor alone or to improve the efficacy of radiation-induced tumor necrosis. Therefore, chemotherapy can lead to tissue damage followed by esophageal wall atrophy, and such changes might increase the risk of stentrelated complications. However, there were no significant difference in term of complications between the number of patients with prior concurrent chemoradiation and patients with prior radiation or chemotherapy alone.

This study has several potential limitations. First, it was a retrospective study performed in a single institution; a prospective, multicenter trial would be of benefit to validate our results. Second, nine of 23 Ultraflex stents (39.1\%) were uncovered and only one of 30 other stents (3.3\%) was uncovered. It is possible that this has an influence on complication rates. However, Vakil et al. ${ }^{34}$ reported that there was no difference in complications of esophageal stent placement, except tumor ingrowth, between the number of patients with covered stent and patients with uncovered stent, so that it likely did not affect the stentrelated complications whether to use covered stent or not. Third, patients with prior concurrent chemoradiation, which might be associated with a greater risk of adverse reactions than prior radiation and chemotherapy alone, were included as in the "prior radiation group." Regardless, this assessment may be appropriate, because significant relations between prior chemotherapy or radiation and complications still exist after multivariate analysis accounts for the effect of confounders.

In conclusion, our results of the clinical research seem to indicate that use of the Ultraflex stent and prior radiation and/or chemotherapy are risk factors for stent-related complications in patients with malignant obstruction of the esophagus and gastric cardia. A prospective, multicenter trial would be of benefit to validate our results.

\section{CONFLICTS OF INTEREST}

No potential conflict of interest relevant to this article was reported.

\section{ACKNOWLEDGEMENTS}

Author contributions: Conception and design: Hiroyasu Iwasaki, Takashi Mizushima; Acquisition of data: Hiroyasu Iwasaki, Yuta Suzuki, Shigeki Fukusada, Kenta Kachi, Takanori Ozeki, Kaiki Anbe; Analysis and interpretation of data: Hiroyasu Iwa- saki, Takashi Mizushima, Hironobu Tsukamoto, Fumihiro Okumura; Drafting the article: Hiroyasu Iwasaki; Revising the article critically for important intellectual content: Takashi Mizushima; Making the decision to submit for publication: Takashi Joh, Hitoshi Sano.

\section{REFERENCES}

1. Knyrim K, Wagner HJ, Bethge N, Keymling M, Vakil N. A controlled trial of an expansile metal stent for palliation of esophageal obstruction due to inoperable cancer. N Engl J Med 1993;329:13021307.

2. Cwikiel M, Cwikiel W, Albertsson M. Palliation of dysphagia in patients with malignant esophageal strictures. Comparison of results of radiotherapy, chemotherapy and esophageal stent treatment. Acta Oncol 1996;35:75-79.

3. Dai Y, Li C, Xie Y, et al. Interventions for dysphagia in oesophageal cancer. Cochrane Database Syst Rev 2014;(10):CD005048.

4. Kinsman KJ, DeGregorio BT, Katon RM, et al. Prior radiation and chemotherapy increase the risk of life-threatening complications after insertion of metallic stents for esophagogastric malignancy. Gastrointest Endosc 1996;43:196-203.

5. Wang MQ, Sze DY, Wang ZP, Wang ZQ, Gao YA, Dake MD. Delayed complications after esophageal stent placement for treatment of malignant esophageal obstructions and esophagorespiratory fistulas. J Vasc Interv Radiol 2001;12:465-474.

6. Nishimura Y, Nagata K, Katano S, et al. Severe complications in advanced esophageal cancer treated with radiotherapy after intubation of esophageal stents: a questionnaire survey of the Japanese Society for Esophageal Diseases. Int J Radiat Oncol Biol Phys 2003;56:1327-1332.

7. Sumiyoshi T, Gotoda T, Muro K, et al. Morbidity and mortality after self-expandable metallic stent placement in patients with progressive or recurrent esophageal cancer after chemoradiotherapy. Gastrointest Endosc 2003;57:882-885.

8. Lecleire S, Di Fiore F, Ben-Soussan E, et al. Prior chemoradiotherapy is associated with a higher life-threatening complication rate after palliative insertion of metal stents in patients with oesophageal cancer. Aliment Pharmacol Ther 2006;23:1693-1702.

9. Fuccio L, Scagliarini M, Frazzoni L, Battaglia G. Development of a prediction model of adverse events after stent placement for esophageal cancer. Gastrointest Endosc 2016;83:746-752.

10. Homs MY, Hansen BE, van Blankenstein M, Haringsma J, Kuipers EJ, Siersema PD. Prior radiation and/or chemotherapy has no effect on the outcome of metal stent placement for oesophagogastric carcinoma. Eur J Gastroenterol Hepatol 2004;16:163-170.

11. Stahl M, Mariette C, Haustermans K, Cervantes A, Arnold D; ESMO Guidelines Working Group. Oesophageal cancer: ESMO Clinical Practice Guidelines for diagnosis, treatment and followup. Ann Oncol 2013;24 Suppl 6:vi51-vi56.

12. Allum WH, Blazeby JM, Griffin SM, et al. Guidelines for the management of oesophageal and gastric cancer. Gut 2011;60:1449- 
1472.

13. Siersema PD, Hop WC, van Blankenstein M, et al. A comparison of 3 types of covered metal stents for the palliation of patients with dysphagia caused by esophagogastric carcinoma: a prospective, randomized study. Gastrointest Endosc 2001;54:145-153.

14. May A, Hahn EG, Ell C. Self-expanding metal stents for palliation of malignant obstruction in the upper gastrointestinal tract: comparative assessment of three stent types implemented in 96 implantations. J Clin Gastroenterol 1996;22:261-266.

15. Verschuur EM, Repici A, Kuipers EJ, Steyerberg EW, Siersema PD. New design esophageal stents for the palliation of dysphagia from esophageal or gastric cardia cancer: a randomized trial. Am J Gastroenterol 2008;103:304-312.

16. Ogilvie AL, Dronfield MW, Ferguson R, Atkinson M. Palliative intubation of oesophagogastric neoplasms at fibreoptic endoscopy. Gut 1982;23:1060-1067.

17. Rustgi AK, El-Serag HB. Esophageal carcinoma. N Engl J Med 2014;371:2499-2509.

18. Liu J, Wang Z, Wu K, et al. Paclitaxel or 5-fluorouracil/esophageal stent combinations as a novel approach for the treatment of esophageal cancer. Biomaterials 2015;53:592-599.

19. Zhu HD, Guo JH, Mao AW, et al. Conventional stents versus stents loaded with (125)iodine seeds for the treatment of unresectable oesophageal cancer: a multicentre, randomised phase 3 trial. Lancet Oncol 2014;15:612-619.

20. Verschuur EM, Steyerberg EW, Kuipers EJ, Siersema PD. Effect of stent size on complications and recurrent dysphagia in patients with esophageal or gastric cardia cancer. Gastrointest Endosc 2007;65:592-601.

21. Conio M, Repici A, Battaglia G, et al. A randomized prospective comparison of self-expandable plastic stents and partially covered self-expandable metal stents in the palliation of malignant esophageal dysphagia. Am J Gastroenterol 2007;102:2667-2677.

22. Homs MY, Wahab PJ, Kuipers EJ, et al. Esophageal stents with antireflux valve for tumors of the distal esophagus and gastric cardia: a randomized trial. Gastrointest Endosc 2004;60:695-702.

23. Sabharwal T, Hamady MS, Chui S, Atkinson S, Mason R, Adam A. A randomized prospective comparison of the Flamingo Wallstent and Ultraflex stent for palliation of dysphagia associated with lower third oesophageal carcinoma. Gut 2003;52:922-926.
24. Schmassmann A, Meyenberger C, Knuchel J, et al. Self-expanding metal stents in malignant esophageal obstruction: a comparison between two stent types. Am J Gastroenterol 1997;92:400-406.

25. Touchefeu Y, Archambeaud I, Landi B, et al. Chemotherapy versus self-expanding metal stent as primary treatment of severe dysphagia from unresectable oesophageal or gastro-oesophageal junction cancer. Dig Liver Dis 2014;46:283-286.

26. Cwikiel W, Willén R, Stridbeck H, Lillo-Gil R, von Holstein CS. Self-expanding stent in the treatment of benign esophageal strictures: experimental study in pigs and presentation of clinical cases. Radiology 1993;187:667-671.

27. Gyöngyösi M, Yang P, Khorsand A, Glogar D. Longitudinal straightening effect of stents is an additional predictor for major adverse cardiac events: Austrian Wiktor Stent Study Group and European Paragon Stent Investigators. J Am Coll Cardiol 2000;35:1580-1589.

28. Hirdes MM, Vleggaar FP, de Beule M, Siersema PD. In vitro evaluation of the radial and axial force of self-expanding esophageal stents. Endoscopy 2013;45:997-1005.

29. Newburger PE, Cassady JR, Jaffe N. Esophagitis due to adriamycin and radiation therapy for childhood malignancy. Cancer 1978;42:417-423.

30. Seaman WB, Ackerman LV. The effect of radiation on the esophagus: a clinical and histologic study of the effects produced by the betatron. Radiology 1957;68:534-541.

31. O'Rourke IC, Tiver K, Bull C, Gebski V, Langlands A0. Swallowing performance after radiation therapy for carcinoma of the esophagus. Cancer 1988;61:2022-2026.

32. Coia LR, Myerson RJ, Tepper JE. Late effects of radiation therapy on the gastrointestinal tract. Int J Radiat Oncol Biol Phys 1995;31: 1213-1236.

33. Byhardt RW, Scott C, Sause WT, et al. Response, toxicity, failure patterns, and survival in five Radiation Therapy Oncology Group (RTOG) trials of sequential and/or concurrent chemotherapy and radiotherapy for locally advanced non-small-cell carcinoma of the lung. Int J Radiat Oncol Biol Phys 1998;42:469-478.

34. Vakil N, Morris AI, Marcon N, et al. A prospective, randomized, controlled trial of covered expandable metal stents in the palliation of malignant esophageal obstruction at the gastroesophageal junction. Am J Gastroenterol 2001;96:1791-1796. 